Research

\title{
Differential gene expression mediated by I 5-hydroxyeicosatetraenoic acid in LPS-stimulated RAW 264.7 cells
}

\author{
Alexandra C Schrimpe and David W Wright*
}

Address: Department of Chemistry, Vanderbilt University, Nashville, Tennessee 37235, USA

Email: Alexandra C Schrimpe - a.schrimpe@vanderbilt.edu; David W Wright* - David.Wright@vanderbilt.edu

* Corresponding author

Published: II August 2009

Malaria Journal 2009, 8:195 doi:10.1186/1475-2875-8-195
Received: 26 March 2009

Accepted: II August 2009

This article is available from: http://www.malariajournal.com/content/8/I/195

(C) 2009 Schrimpe and Wright; licensee BioMed Central Ltd.

This is an Open Access article distributed under the terms of the Creative Commons Attribution License (http://creativecommons.org/licenses/by/2.0), which permits unrestricted use, distribution, and reproduction in any medium, provided the original work is properly cited.

\begin{abstract}
Background: Given the immuno-modulatory activity of native haemozoin $(\mathrm{Hz})$, the effects of constitutive $\mathrm{Hz}$ components on immune response are of interest. Recently, gene expression changes mediated by $\mathrm{HNE}$ and the synthetic analogue of $\mathrm{Hz}$, beta-haematin $(\mathrm{BH})$, were identified and implicated a significant role for lipid peroxidation products in $\mathrm{Hz}$ 's activity. The study presented herein examines gene expression changes in response to 15(S)-hydroxyeicosatetraenoic acid (HETE) in a model macrophage cell line.
\end{abstract}

Methods: LPS-stimulated RAW 264.7 macrophage-like cells were treated with $40 \mu \mathrm{M}$ I5(S)-HETE for $24 \mathrm{~h}$, and microarray analysis was used to identify global gene expression alterations. Fold changes were calculated relative to LPS-stimulated cells and those genes altered at least I.8-fold ( $p$ value $\leq 0.025$ ) were considered to be differentially expressed. Expression levels of a subset of genes were assessed by qRT-PCR and used to confirm the microarray results.

Results: Network analysis revealed that altered genes were primarily associated with "lipid metabolism" and "small molecule biochemistry". While several genes associated with PPAR-gamma receptor-mediated signaling were differentially expressed, a number of genes indicated the activation of secondary signaling cascades. Genes related to cytoadherence (cell-cell and cellmatrix), leukocyte extravasation, and inflammatory response were also differentially regulated by treatment, supporting a potential role for $15(\mathrm{~S})$-HETE in malaria pathogenesis.

Conclusion: These results add insight and detail to 15-HETE's effects on gene expression in macrophage-like cells. Data indicate that while 15-HETE exerts biological activity and may participate in $\mathrm{Hz}$-mediated immuno-modulation, the gene expression changes are modest relative to those altered by the lipid peroxidation product HNE.

\section{Background}

Although haem is a vital cofactor for a diverse set of proteins involved in respiration, oxygen transport, and drug detoxification, the accumulation of free haem has deleterious effects. Haem is capable of binding to lipid bilayers, catalyzing lipid peroxidation, inhibiting enzymatic activity, and lysing cells and parasites [1,2]. Many organisms utilize the haem oxygenase pathway to degrade free haem. Blood-feeding Plasmodium parasites, the source of malaria infection, lack such a pathway. Consequently, haem 
released during haemoglobin catabolism is sequestered as the insoluble crystalline "malaria pigment" (i.e., haemozoin $[\mathrm{Hz}])$. As most of the haem is occluded within the crystal, the parasite is protected.

$\mathrm{Hz}$ is composed of five-coordinate $\mathrm{Fe}$ (III) protoporphyrin IX dimers covalently bound by reciprocal iron-carboxylate bonds [3]. The remaining propionate side chains of adjacent dimers form hydrogen bonds, resulting in an extended dimeric network producing the $\mathrm{Hz}$ crystal. In its native state, $\mathrm{Hz}$ is coated by an array of host- and parasitederived lipids, proteins, and nucleic acids [4]. Analysis of the lipid component identified peroxidation products including a racemic mixture of 5-, 8-, 9-, 11-, 12-, and 15hydroxyeicosatetraenoic acids (HETEs) and 9- and 13hydroxyoctadecadienoic acids (HODEs) [5]. Elevated levels of 4-hydroxynonenal (HNE) were also detected in haemozoin-laden monocytes [6] at the highest reported concentration of any biological system to date [7].

Rupture of parasitized red blood cells (RBCs) releases cellular debris, including residual bodies containing $\mathrm{Hz}$, into the host's vasculature and triggers an innate immune response. The typical response of phagocytic cells to such foreign material includes oxidative burst and rephagocytosis, however, phagocytosis of $\mathrm{Hz}$ impairs these innate functions [8-10]. It has been suggested that Hz's immunological activity may not stem from the haem moiety but from nonspecific toxins [11], such as lipid peroxidation products, present on its surface and introduced into the cell during phagocytosis

The cellular response to several lipid peroxidation species associated with $\mathrm{Hz}$ is well documented and indicates an involvement in malaria pathophysiology. Recently, two components of native $\mathrm{Hz}$ were targeted as potential players involved in macrophage dysfunction [12]. Microarray analysis of the response to HNE and Hz's biologically naive synthetic analogue, $\beta$-haematin $(\mathrm{BH})$, indicated a potential role for HNE in malaria pathogenesis. It seemed probable, given HNE-mediated gene expression changes, that other biologically active lipid peroxidation products generated by $\mathrm{Hz}$, including 15 -HETE, may be active in the disease's pathogenesis.

Macrophage-like cells treated with 15-HETE exhibited impaired PMA-activated NADPH oxidase and LPS-stimulated inducible nitric oxide synthase (iNOS) activities, mimicking Hz-mediated monocyte immunomodulation [13]. 15-HETE was also reported to enhance vascular permeability/oedema [14] and RBC adherence to endothelia [15], two hallmarks of malarial infection. The present study examined steady-state gene expression changes induced by 15-HETE in activated RAW 264.7 model mac- rophage cells in the context of a nonspecific malaria toxin that may be involved in disease pathophysiology.

\section{Methods \\ Cell culture}

Murine macrophage-like RAW 264.7 cells (American Type Culture Collection TIB-71, Monassas, VA) were cultured under standard incubation conditions $\left(37^{\circ} \mathrm{C}, 5 \% \mathrm{CO}_{2}\right)$ and grown in RPMI supplemented with $10 \%$ FBS (Atlanta Biologicals, Atlanta, GA) and $1 \mu \mathrm{g} / \mathrm{mL} \mathrm{P} / \mathrm{S}$ (Cellgro MediaTech, Herndon, VA). Cells were plated at a density of $4 \times$ $10^{6}$ cells/well in six well plates and incubated for $24 \mathrm{~h}$ prior to treatment.

\section{Cell treatment and RNA isolation}

Cells were washed once with Dulbecco's PBS (DPBS) and treated with $40 \mu \mathrm{M}$ 15(S)-HETE. Immediately following treatment, LPS was added to all wells at a final concentration of $1 \mu \mathrm{g} / \mathrm{mL}$. After $24 \mathrm{~h}$, cells were washed three times with DPBS and scraped from the wells. Three biological replicates (composed of six pooled wells each) per sample were prepared. Total RNA was isolated using the Versagene RNA purification and DNase treatment kits, following the manufacturer's recommendations.

\section{Microarray analysis}

Microarray analysis was performed by the Vanderbilt Microarray Shared Resource. Three biological replicates of each treatment were analyzed for quality (Agilent 2100 Bioanalyzer, Agilent Technologies, Palo Alto, CA). One microgram of total RNA (30 ng mRNA) was used to generate first strand cDNA using the NanoAmp RT-IVT labeling kit according to the manufacturer's protocol. Following first strand synthesis, second strand synthesis was completed. The resulting cDNA was then purified using an ABI kit-provided column and the entire reaction was used in an IVT reaction to generate DIG-labeled cRNA. The cRNA was then purified using a kit-provided column and assessed for quality on an Agilent Bioanalyzer. All reactions meeting ABI criteria in terms of quantity and size of target produced were fragmented and then hybridized to an ABI mouse genome survey microarray for $16 \mathrm{~h}$ with agitation at $55^{\circ} \mathrm{C}$ per the manufacturer's protocol. Following the addition of the chemiluminescence reaction substrate, each array was immediately imaged on the 1700 Chemiluminescent Analyzer, and a primary analysis was completed by the AB1700 Expression Array System Software (v 1.1.1). Expression values were quantile normalized and filtered based on $\mathrm{S} / \mathrm{N}(>3)$ and flag value $(<5000)$. GeneSpring GX 7.3.1 software (Agilent Silicon Genetics, Redwood City, CA) was used to determine statistically significant differentially expressed genes. T-tests were performed on probes altered by $\geq 1$.8fold in 2 of 3 samples (0.025 $p$ value cut-off, Benjamini- 
Hochberg multiple testing correction, parametric test, variances not assumed equal) in treated stimulated cells (experimental) relative to stimulated cells (control). Genes were classified according to genes ontology (GO) terms using GeneSpring. In accordance with MIAME procedure, microarray data have been submitted to the NCBI Gene Expression Omnibus and can be found under series number GSE15070. Nomenclature for genes and proteins is as described by the Mouse Genome Informatics (MGI) database guidelines.

\section{Ingenuity pathway analysis}

Ingenuity Pathways Analysis (IPA) was used for gene expression analysis (Ingenuity Systems ${ }^{\circledR}$ ). A data set containing gene identifiers and corresponding expression values was uploaded into the application, and each identifier was mapped to its corresponding gene object in the Ingenuity knowledge base (IKB). A functional analysis was performed to determine biological functions that were most significant to the genes in the data set. A network analysis was also performed whereby focus genes were overlaid onto a global molecular network developed from information contained in the IKB. Networks of focus genes were then algorithmically generated based on their connectivity. A functional analysis of each network identified the biological functions that were most significant to the genes in the network, and canonical pathway analysis identified the pathways from the IPA library of canonical pathways that were most significant to the data set. Fischer's exact test was used to calculate a $p$ value determining the probability that that each biological function assigned to a network or data set, or the association between the genes in the data set and the canonical pathway, are explained by chance alone.

\section{Real-time reverse transcription polymerase chain reaction} Quantitative real-time reverse transcription polymerase chain reaction (qRT-PCR) was used to validate the expression levels of genes identified as differentially expressed by microarray analysis. Quadruplicate measurements for $\mathrm{n}=3$ independent biological replicates per sample were performed. cDNA was reverse-transcribed from $0.5 \mu \mathrm{g}$ of total RNA using random hexamer primers and Superscript II Reverse Transcriptase (Invitrogen). Reactions were purified using Qiagen's PCR Purification Kit following the manufacturer's protocol. Following RT, all assays were performed with Applied Biosystems TaqMan FAM labeled 20× probes: Arf3 (Taqman assay Mm00500194_m1), Cldn11 (Mm00500915 m1), Cxcl11 (Mm00444662_m1), Mapk14 (Mm00442497_m1), Prdx1 (Mm01621996_s1), Sdc1 (Mm00448918_m1), and Egr1 (Mm00656724_m1). Ywhaz was chosen as the endogenous control based on results obtained from an Applied Biosystems mouse endogenous control array.

cDNA amplification was performed using TaqMan $2 \times$ Universal PCR Master Mix (Applied Biosystems), and standard Taqman cycling conditions were used as specified by the manufacturer. Cycling and data collection were performed using the Applied Biosystems 7900 HT instrument, and analysis was performed using SDS software to calculate $\mathrm{Ct}$ values for each detector. $\mathrm{Ct}$ values were processed based on the comparative Ct method where the relative transcript level of each target gene was calculated according to the equation $2^{-\Delta \mathrm{Ct}}$, where $\Delta \mathrm{Ct}$ is defined as $\mathrm{Ct}$ target gene - Ct Ywhaz.

\section{Results}

\section{Functional analysis of gene expression changes induced by I5(S)-HETE}

LPS-stimulated macrophage-like RAW 264.7 cells were treated for $24 \mathrm{~h}$ with $40 \mu \mathrm{M} 15$ (S)-HETE based on the estimate that trophozoites and $\mathrm{Hz}$ contained 33-39 $\mu$ mol 15HETE/L RBC [5]. Statistically significant ( $p \leq 0.025)$ changes in gene expression (fold change $\geq 1.8$ relative to stimulated cells) were identified by microarray analysis. Given that this study aims to explore potential alterations in gene expression that are incurred by 15-HETE during haemozoin phagocytosis, differentially expressed mRNAs were controlled by comparison with a particulate latex bead challenge and $\mathrm{BH}$ treatment under the same conditions. Figure 1 illustrates that 15-HETE had a much greater effect on induction of gene expression than repression (293 transcripts versus 100 transcripts, respectively), but overall was very modest compared to either latex bead or $\mathrm{BH}$ treatment.

A

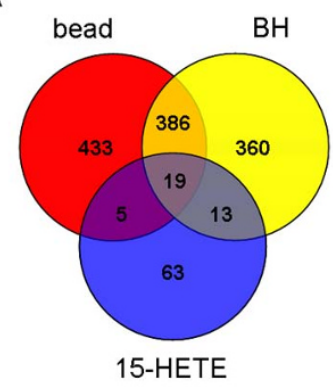

Figure I

Comparison of differentially expressed genes mediated by I5-HETE, beta-haematin, and latex beads. Venn diagrams show the intersection of genes that were transcriptionally altered by $40 \mu \mathrm{M}$ I5-HETE with those altered by latex bead treatment and serum-opsonized beta haematin $(\mathrm{BH})(0.1 \mathrm{mg} / \mathrm{mL})$. Numbers represent statistically significant $(p \leq 0.025)$ transcripts up- or down-regulated $\geq$ I.8-fold in 2 of 3 samples, relative to LPS-stimulated untreated cells at $24 \mathrm{~h}$. (A) Decreased and (B) increased expression are shown separately. 
Ingenuity Pathway Analysis (IPA) software was used to examine biological relationships associated with 15HETE-mediated expression changes. Identifiers and relative levels of altered genes comprising the data set were imported and mapped by IPA for comparison to molecules within the Ingenuity knowledge base (IKB). Two types of IPA analyses were performed. First, a network analysis was employed to reveal direct and indirect relationships that exist between specific genes in the data set. This analysis resulted in the generation of a network map which illustrates direct and indirect connections between focus genes. Second, a functional analysis was performed to identify the biological processes that are most relevant to the entire set of differentially expressed genes. This analysis resulted in a list of significant biological functions associated with the data set as a whole. Functional analyses were also used to find biological processes associated with individual networks. Focus genes, imported genes that are eligible for generating interaction networks based on incorporation in IKB, were used to identify relationships based on known interactions in the literature. Each network is associated with a score indicating the likelihood that the focus genes occur in the network by random chance. Networks scoring 10 or higher (score is defined as -log ( $p$ value)) are considered significant.
Among the transcripts modulated by 15-HETE treatment, 263 were eligible for network analysis based on IPA criteria, mapping to 11 relevant interaction networks. The most significant network (Figure $2 \mathrm{a}$ ) had a score of 51 and associated 27 focus genes. Several transcriptional regulators were among the products encoded by these genes (Bclaf1, Med1, Noc2l, Rnf4, and Zfp36l1). This network also contained Il1b, Cyp3a4, Gnas, and Adfp. A functional analysis performed on this particular network indicated that the differentially expressed genes were associated with "lipid metabolism" and "small molecule biochemistry" $\left(\mathrm{p}=1.27 \times 10^{-4}\right)$.

Figure $2 \mathrm{~b}$ shows the second most significant interaction network identified by IPA network analysis. Eighteen focus genes were incorporated into the network with a score of 29. Functional analysis of the network revealed that the genes were involved in "molecular transport" ( $\mathrm{p}$ $\left.=9.42 \times 10^{-7}\right)$ and "cellular movement" $\left(\mathrm{p}=9.77 \times 10^{-6}\right)$. This network is enriched with focus genes encoding molecules associated with the plasma membrane such as Pkd2, Cd300a, Cldn11, Gypc, Klra4, peptidase Adam9 and transporters Atp1a2, Slc16a1, and Slc16a3. Consistent with these genes, the network predicted interactions with several other plasma membrane molecules (Tjp2, Bsg,
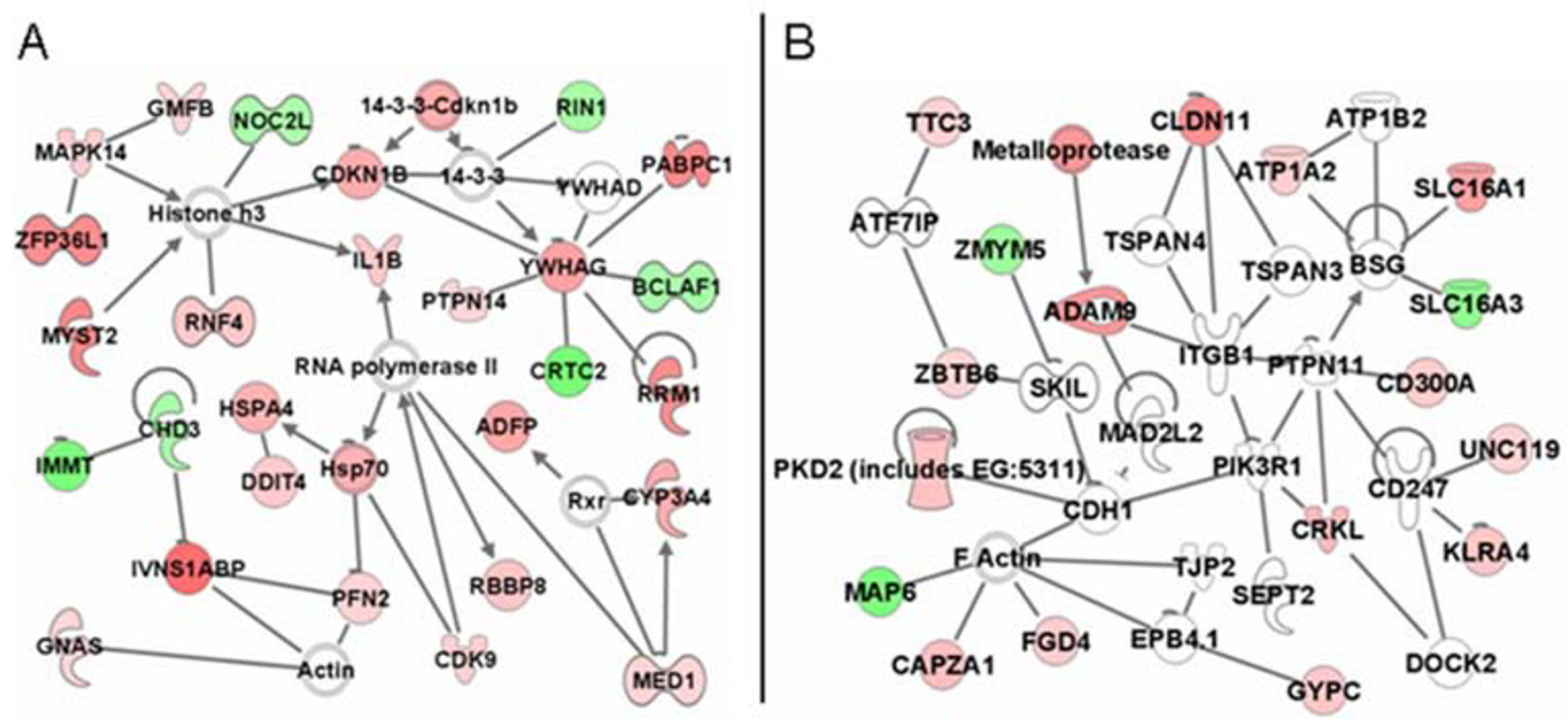

\section{Figure 2}

Ingenuity Pathway network analysis. Transcripts altered $\geq 1.8$-fold $(p \leq 0.025)$ in I5-HETE-treated RAW 264.7 cells (i.e., focus genes) were overlaid onto a global molecular network developed from information contained in the Ingenuity knowledge base (IKB). Networks of these focus genes were algorithmically generated based on their connectivity. Networks show direct interactions between focus genes altered by I5-HETE treatment and associated molecules within the IKB. Genes or gene products are represented as nodes, and the biological relationship between two nodes is represented as an edge (line). White nodes represent IKB molecules that are associated with focus genes. All edges are supported by at least one reference stored in the IKB. The intensity of node color indicates the degree of up- (red) or down- (green) regulation. Networks reflect (A) lipid metabolism and small molecule biochemistry and (B) molecular transport and cellular movement. 
Cdh1, Tspan3, Tspan4, Cd247, Itgb1, and Atp1b2) that were not present in the data file.

Molecular and cellular functions controlled by I5(S)-HETE It is thought that $\mathrm{Hz}$ impairs cellular function through the generation and introduction of toxic species such as lipid peroxidation products into cells. Previously, the ability of HNE to stimulate a transcriptional response was examined in macrophage-like cells [12]. It was observed that HNE significantly impacted a wide range of steady-state responses (e.g., macrophage activation, immune and inflammatory responses, NF-кB signal transduction, ECM degradation, and dyserythropoiesis). Comparison of the number of gene expression changes influenced by 15 HETE and HNE indicates that 15-HETE modulates a number of mRNA targets but is a much less potent agent than HNE (Figure 3).

IPA was also used to perform a functional analysis on genes within the entire data set. Comparison of the biological functions modulated by 15-HETE (Table 1) and HNE [12] revealed that 15-HETE affected a considerably smaller group of transcripts than HNE but mediated a comparable response in terms of the number of molecular and cellular functions and the specific categories affected. Both lipid peroxidation products altered "Cell Cycle", "Cell Morphology", "Cellular Assembly and Organization", "Cell Death", "Cellular Development", "Cell Growth and Proliferation", "Gene Expression", and "Small Molecule Biochemistry". 15-HETE affected several unique categories including "Carbohydrate Metabolism", "Drug Metabolism", "Lipid Metabolism", "Molecular Transport", "RNA Damage and Repair", and "RNA PostTranslational Modification".

Both IPA network and functional analyses identified a large group of "lipid metabolism" and "carbohydrate
A

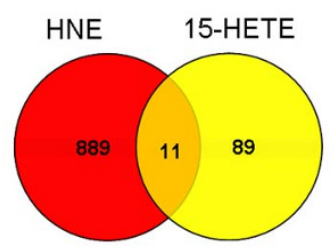

B

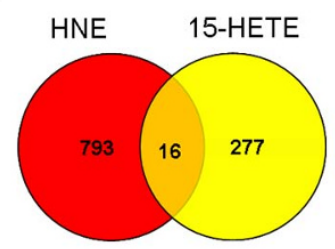

Figure 3

Comparison of differentially expressed genes mediated by I5-HETE and HNE. Data sets for each treatment group ( $15-\mathrm{HETE}$ or HNE) were generated from statistically significant $(p \leq 0.025)$ transcripts up- or down-regulated $\geq$ 1.8-fold in 2 of 3 samples relative to untreated LPS-stimulated cells. Venn diagrams show intersections of the resulting I5-HETE and HNE data subsets. (A) Decreased and (B) increased expression are shown separately.
Table I: Functional Analysis of I5-S-HETE Data Set ${ }^{a}$

\begin{tabular}{ll}
\hline Biological Function & $p$ value \\
\hline carbohydrate metabolism & $6.42 \times 10^{-6}$ \\
cell cycle & $1.28 \times 10^{-4}$ \\
cell death & $1.93 \times 10^{-5}$ \\
cell morphology & $2.53 \times 10^{-4}$ \\
cellular assembly and organization & $5.30 \times 10^{-4}$ \\
cellular compromise & $4.52 \times 10^{-4}$ \\
cellular development & $3.42 \times 10^{-5}$ \\
cellular growth and proliferation & $3.81 \times 10^{-4}$ \\
drug metabolism & $3.81 \times 10^{-4}$ \\
gene expression & $2.22 \times 10^{-4}$ \\
lipid metabolism & $1.25 \times 10^{-3}$ \\
molecular transport & $3.81 \times 10^{-4}$ \\
RNA damage and repair & $3.79 \times 10^{-4}$ \\
RNA post-transcriptional modification & $3.79 \times 10^{-4}$ \\
small molecule biochemistry & $3.81 \times 10^{-4}$ \\
\hline
\end{tabular}

${ }^{a}$ Ingenuity Pathway Analysis uses a right-tailed Fisher exact test to calculate $p$ values. Significance values for each data set indicate the probability that the association between the genes and the given biological function is due to random chance.

metabolism" expression changes. Given that $I l 1 b$ acts upstream of Cyp3a4, Ugdh, Gnas, Gm2a, Psen1, and Il15, stimulated $I l 1 b$ expression may be indirectly involved in the up-regulation of each of these genes in this study. Expression of several "small molecule biochemistry" transcriptional regulators (Bclaf1, Med1, Rnf4, Noc2l, and Zfp36l1) was also identified.

\section{Differential gene expression in the context of malaria pathogenesis}

Differentially expressed genes were sorted into lists based on the direction of regulation, and corresponding Gene Ontology (GO) categories were identified. Gene expression alterations mediated by 15-HETE were compared to two groups of transcripts. The first group consisted of specific genes or gene products associated with human [16] or murine $[17,18]$ models of malarial infection or $\mathrm{Hz}$ exposure [19]. Common transcripts were primarily associated with "cell-to-cell signaling and interaction" and "immune response" (e.g., Fcgrt, Cd86, C5ar1, Ccr4, Mapk14, Pik3ap1, Tapbp, and Tnfaip6). Enhanced expression of guanylate nucleotide binding proteins $(G b p) 1$ and 3 observed in this study was consistent with expression changes reported in human and experimental murine malaria $[16-18,20]$. The second group included genes classified under specific GO processes that are overexpressed in the Plasmodium yoelii model [20] and/or naturally acquired Plasmodium falciparum infections [21], including cell-cell signaling, defense response, immune response, inflammatory response, and signal transduction, among others. Differential expression mediated by 15-HETE treatment that correlated with either of the two 
groups described above is listed in Table 2 . The relatively limited correlation reflects differences between 15-HETEmediated expression changes in this model and expression changes observed during naturally acquired or experimental malaria. While RAW 264.7 cells have previously been shown to mimic monocyte/macrophage immunomodulation in the presence of HNE [12], the findings presented herein suggest that 15-HETE is not a major contributor to the altered immune response observed in these cells types during infection.

\section{Validation of microarray results}

qRT-PCR was used to confirm several genes susceptible to differential regulation by 15 -HETE. The analysis focused on selected genes implicated in the host response to malaria. The results shown in Figure 4 are expressed as fold change relative to LPS-stimulated cells. In agreement with the microarray results in terms of magnitude and direction of change, 15-HETE stimulated the expression of Arf3 (ADP-ribosylation factor 3), Cldn11 (claudin 11), Cxcl11 (chemokine (C-X-C motif) ligand 11), Mapk14 (mitogen-activated protein kinase 14), $\operatorname{Prdx} 1$ (peroxiredoxin 1), and $S d c 1$ (syndecan 1) and repressed the expression of Egr1 (early growth response 1).

\section{Discussion}

Global responses to malaria infection have been examined at the molecular level in the blood of human victims $[16,21]$, malaria positive tissue [22], and both murine $[17,18,20]$ and monkey [23] malaria models using microarray technology. Perturbations of gene expression associated with erythropoiesis, glycolysis, metabolism, B-cell activation, and inflammation were frequently identified in these analyses; however, the specific agents responsible for mediating expression changes remain unknown. Accumulating evidence supports the hypothesis that many of the adverse effects of malaria are not caused directly by the parasite, but by endogenous toxins generated during interactions with parasite-derived species such as $\mathrm{Hz}$ [24].

The immuno-modulatory response to native $\mathrm{Hz}$ has been recapitulated using individual components of $\mathrm{Hz}$ (i.e., membrane lipids from erythrocyte ghosts incubated with $\mathrm{BH}$ ) in a model system [13]. Macrophage-like cells treated with the reaction supernatant exhibited a dose-dependent impairment of PMA-activated NADPH oxidase and LPSstimulated iNOS activities. Neither BH- nor ghost-supernatant alone altered NADPH or iNOS activity, indicating that lipid peroxidation products generated during reactions between $\mathrm{BH}$ and ghost membranes were responsible for the inhibitory effects. Several laboratories have shown that biologically relevant levels of the individual lipid peroxidation products HNE and 15-HETE were capable of mimicking the dysfunctional response to $\mathrm{Hz}$ phagocytosis, suggesting the basis of $\mathrm{Hz}$ activity $[13,25,26]$.
Considering these results, global responses to individual $\mathrm{Hz}$ constituents are of particular interest. The ability of specific and nonspecific malaria toxins to stimulate changes in gene expression has recently been examined in macrophage-like cells [12]. Microarray analyses of two individual $\mathrm{Hz}$ components (i.e., $\mathrm{BH}$ and $\mathrm{HNE}$ ) indicated that while $\mathrm{BH}$ primarily elicited a phagocytic response, HNE significantly perturbed a myriad of biological processes. These results substantiated further exploration of a potential role for the $\mathrm{Hz}$-associated lipid peroxidation product 15-HETE.

In the current study, activated RAW 264.7 macrophagelike cells were treated with 15-HETE, and mRNA levels were assessed at $24 \mathrm{~h}$ to mimic a steady-state response that would be relevant to an established malaria infection. IPA software was utilized to perform complementary network (Figure 2) and functional (Table 1) analyses for identification of biological relationships within the data. Figure 3 shows that the number of expression changes mediated by 15-HETE was modest relative to the previously reported global response to HNE [12]. Unlike the mode of action behind HNE's biological activity (forming adducts to cellular nucleophiles and subsequently modulating intracellular signaling), 15-HETE serves as a ligand for the nuclear PPAR $\gamma$ receptor [27]. As expected, downstream PPAR $\gamma$ signaling transcripts (e.g., Adfp, Ca2, Cyp3a4, M6pr, M6prbp1, $M e d 1, M e d 7$, and $S d c 1$ ) were elevated in response to 15HETE.

\section{Cytoadherence}

A balance between removal of Plasmodium from circulation and sequestration inside host cells is crucial for parasite survival during infection. Sequestration is mediated by cytoadherence, specifically, the adherence of parasitized RBCs (PRBCs) and leukocytes to capillary and postcapillary venular endothelial cells (EC). This cytoadherence reduces blood flow and causes metabolic dysfunction [28] and is thought to be a major factor associated with cerebral malaria (CM). The mechanism(s) used for adhesion and migration involve the expression of constitutive ligands (i.e., adhesion molecules) and receptors on PRBCs or leukocytes and EC. Cell-cell and cell-matrix interactions are also mediated by the secretion of microbial products or cytokines, which enhance the expression of inducible adhesion molecules.

Investigation of potential arachidonic acid metabolite involvement in cytoadherence identified 15-HETE as an agent capable of stimulating basal adhesion of erythrocytes [15] and monocytes to EC [29,30]. In this study, 15HETE induced the expression of several transcripts involved in integrin signaling (e.g., Crkl, Rap2b, Arf3). The expression of genes encoding $P k d 2$ and $S d c 1$, which are involved in cell-cell and cell-matrix interactions, and 
Table 2: Select Gene Expression Changes Mediated by I5-HETE ${ }^{a}$

\begin{tabular}{|c|c|c|c|c|c|}
\hline Gene Symbol & Fold Change & Probe ID & Description & Entrez ID & Ref \\
\hline \multicolumn{6}{|c|}{ Electron Transport [2I] } \\
\hline Cyp3alı & 3.6 & 516253 & Cytochrome P450, family 3 , subfamily a, polypeptide II & 13112 & \\
\hline Smox & 5.1 & 560410 & Spermine oxidase & 228608 & \\
\hline Ugdh & 1.9 & 500013 & UDP-glucose dehydrogenase & 22235 & \\
\hline \multicolumn{6}{|c|}{ Regulation of Transcription, DNA-Dependent [2I] } \\
\hline Bclafl & -1.9 & 549609 & $\mathrm{BCL2}$-associated transcription factor I & 72567 & \\
\hline Cdk9 & 2.1 & 392872 & Cyclin-dependent kinase 9 (CDC2-related kinase) & $10795 \mid$ & \\
\hline Cregl & 1.9 & 760346 & Cellular repressor of EIA-stimulated genes I & 433375 & \\
\hline Egrl & -4.7 & 524988 & Early growth response I & 13653 & \\
\hline FbxllI & -2.9 & 464056 & F-box and leucine-rich repeat protein II & 225876 & \\
\hline Flil & 2.3 & 407869 & Friend leukemia integration I & 14247 & \\
\hline Fliih & 4.6 & 706377 & Flightless I homologue (Drosophila) & 14248 & \\
\hline $\mathrm{HIxI}$ & 2.1 & 915372 & H2.0-like homeo box I (Drosophila) & 15284 & \\
\hline Mxdl & 2.1 & 520449 & MAX dimerization protein I & 17119 & \\
\hline Myst2 & 5.4 & 494053 & MYST histone acetyltransferase 2 & 217127 & \\
\hline Pou $2 f 2$ & -4.4 & 911620 & POU domain, class 2 , transcription factor 2 & 18987 & \\
\hline Pparbp & 1.9 & 553770 & Peroxisome proliferator activated receptor binding protein & 19014 & \\
\hline Pspcl & 2.0 & 474771 & Paraspeckle protein I & 66645 & \\
\hline Rablla & 2.0 & 359489 & RABI Ia, member RAS oncogene family & 53869 & \\
\hline Rnf4 & 2.5 & 567180 & Ring finger protein 4 & 19822 & \\
\hline Tsc22d3 & 2.0 & 700170 & TSC22 domain family 3 & 14605 & \\
\hline Zfp482 & 2.0 & 435236 & Zinc finger protein 482 & 241322 & \\
\hline \multicolumn{6}{|c|}{ Protein Biosynthesis [20,2I] } \\
\hline Eprs & 4.9 & 455664 & Glutamyl-prolyl-tRNA synthetase & 107508 & \\
\hline \multicolumn{6}{|c|}{ Protein Folding [2I] } \\
\hline Clpx & 2.4 & 733670 & Caseinolytic peptidase $X(E$. coli) & 270166 & \\
\hline Hspa4 & 3.5 & 578003 & Heat shock protein 4 & 15525 & \\
\hline \multicolumn{6}{|c|}{ Ubiquitin Cycle [2I] } \\
\hline Cul7 & 0.4 & 742757 & Cullin 7 & 66515 & \\
\hline Fbxo3 & 1.9 & 832607 & F-box only protein 3 & 57443 & \\
\hline Ube216 & 2.0 & 401185 & Ubiquitin-conjugating enzyme E2L 6 & 56791 & [16] \\
\hline \multicolumn{6}{|c|}{ Intracellular Protein Transport [2I] } \\
\hline Apls2 & 2.0 & 605927 & Adaptor-related protein complex I, sigma 2 subunit & 108012 & \\
\hline Arf3 & 4.4 & 652348 & ADP-ribosylation factor 3 & 11842 & \\
\hline Sortl & 2.4 & 339169 & Sortilin I & 20661 & \\
\hline \multicolumn{6}{|c|}{ Response to Stress [2I] } \\
\hline MapkI4 & 2.2 & 755610 & Mitogen activated protein kinase 14 & 26416 & [16] \\
\hline Prdxl & 2.1 & 530413 & Peroxiredoxin I & 18477 & [17] \\
\hline $\operatorname{Prdx6}$ & -2.0 & 825043 & Peroxiredoxin 6 & 11758 & \\
\hline \multicolumn{6}{|c|}{ Defense Response [20,2I] } \\
\hline Bstl & 2.1 & 837914 & Bone marrow stromal cell antigen I & 12182 & \\
\hline KIral8 & 2.5 & 806675 & Killer cell lectin-like receptor, subfamily A, member 18 & 93970 & \\
\hline Tapbp & 2.0 & 928057 & TAP binding protein & 21356 & [20] \\
\hline
\end{tabular}


Table 2: Select Gene Expression Changes Mediated by I5-HETEa (Continued)

\begin{tabular}{|c|c|c|c|c|c|}
\hline \multicolumn{6}{|c|}{ Inflammatory Response [20,2I] } \\
\hline Abcbla & 2.6 & 677412 & ATP binding cassette, sub-family $B(M D R / T A P)$, member IA & 97570 & \\
\hline $\mathrm{Ca} 2$ & 4.0 & 574832 & Carbonic anhydrase 2 & 88269 & \\
\hline Card I2 & 2.2 & 336709 & Caspase recruitment domain family, member 12 & 268973 & \\
\hline Cdknlb & 3.7 & 516253 & Cytochrome P450, family 3, subfamily a, polypeptide II & 104565 & \\
\hline Clu & 4.0 & 379462 & Clusterin & 88423 & \\
\hline CrII & 1.9 & 538208 & Complement component $(3 \mathrm{~b} / 4 \mathrm{~b})$ receptor I-like & 88513 & \\
\hline Сyp3all & 3.7 & 516253 & Cytochrome P450, family 3, subfamily a, polypeptide II & 88609 & \\
\hline Fyn & 2.50 & 766362 & Fyn proto-oncogene & 95602 & \\
\hline H2-Q8 & 1.8 & 712519 & Histocompatibility $2, \mathrm{Q}$ region locus 8 & 95937 & \\
\hline Hnrnpa3 & 4.8 & 903894 & Heterogeneous nuclear ribonucleoprotein $\mathrm{A} 3$ & $191717 \mid$ & \\
\hline $\mathrm{Mrcl}$ & 2.9 & 331550 & Mannose receptor, $\mathrm{C}$ type I & 97142 & \\
\hline Pole4 & 2.3 & 508321 & Polymerase (DNA-directed), \& 4 (pI2 subunit) & 1914229 & \\
\hline Ppp3rl & 2.7 & $7|654|$ & Protein phospatase 3 , regulatory subunit $B, \alpha$ isoform (calcineurin $B$, type $I$ ) & 107172 & \\
\hline Procr & 2.0 & 431405 & Protein $C$ receptor, endothelial & 104596 & \\
\hline Rrml & 5.6 & 865694 & Ribonucleotide reductase $\mathrm{MI}$ & 98180 & \\
\hline Serpinb2 & 4.0 & 860577 & Serine (or cysteine) proteinase inhibitor, clade B, member 2 & 97609 & \\
\hline \multicolumn{6}{|c|}{ Leukocyte Extravasation and Signalling } \\
\hline Arhgap 12 & 2.2 & 465731 & $\rho$ GTPase activating protein 12 & 1922665 & \\
\hline Crkl & 3.0 & 389169 & V-crk sarcoma virus CTIO oncogene homologue (avian)-like & 104686 & \\
\hline Ptk2b & 2.6 & 867483 & PTK2 protein tyrosine kinase $2 \beta$ & 104908 & \\
\hline \multicolumn{6}{|c|}{ Immune Response $[20,21]$} \\
\hline CxcllI & 5.1 & 921243 & Chemokine (C-X-C motif) ligand II & 56066 & \\
\hline Ddx58 & 7.1 & 438990 & DEAD (Asp-Glu-Ala-Asp) box polypeptide 58 & 230073 & \\
\hline Fcgrt & 2.0 & 390657 & Fc receptor, lgG, $\alpha$ chain transporter & 14132 & {$[16]$} \\
\hline Gbpl & 2.9 & 586296 & Guanylate nucleotide binding protein I & 14468 & {$[16,18,20$} \\
\hline Gbp3 & 3.0 & 405120 & Guanylate nucleotide binding protein 3 & 55932 & {$[17,20]$} \\
\hline Ifit3 & 3.2 & 888038 & Interferon-induced protein with tetratricopeptide repeats 3 & 15959 & \\
\hline $\mathrm{IIIa}$ & 5.1 & 595893 & Interleukin I $\alpha$ & 96542 & \\
\hline IIIb & 2.4 & 734612 & Interleukin I $\beta$ & 16176 & \\
\hline 1115 & 1.9 & 876196 & Interleukin 15 & 16168 & \\
\hline \multicolumn{6}{|c|}{ Cell Cycle [20] } \\
\hline Ccnf & 2.4 & 767163 & Cyclin F & 12449 & \\
\hline Cdknlb & 3.7 & 704876 & Cyclin-dependent kinase inhibitor IB (P27) & 12576 & \\
\hline Pmp22 & 1.9 & 616997 & Peripheral myelin protein & 18858 & \\
\hline Rhob & -2.2 & 925472 & Ras homologue gene family, member B & 11852 & \\
\hline \multicolumn{6}{|c|}{ Cell Adhesion [2I] } \\
\hline CldnII & 4.9 & 338333 & Claudin II & 18417 & \\
\hline Scarb2 & 2.5 & $56 \mid 450$ & Scavenger receptor class $B$, member 2 & 12492 & \\
\hline Tnfaip6 & 1.9 & 614886 & Tumor necrosis factor alpha induced protein 6 & 21930 & {$[16]$} \\
\hline \multicolumn{6}{|c|}{ Signal Transduction [20] } \\
\hline Ccr4 & 2.2 & 618105 & Chemokine ( $\mathrm{C}-\mathrm{C}$ motif) receptor 4 & 12773 & {$[18]$} \\
\hline $\mathrm{Cd} 86$ & 3.2 & 908805 & Cd86 antigen & 12524 & {$[20,22]$} \\
\hline Gnas & 1.8 & 646267 & GNAS (guanine nucleotide binding protein, alpha stimulating) complex locus & 14683 & \\
\hline Ms4a4c & 2.8 & $\begin{array}{l}791872 \\
495283\end{array}$ & Membrane-spanning 4-domains, subfamily A, member 4C & 64380 & \\
\hline Olfr472 & -2.2 & 591718 & Olfactory receptor 472 & 258770 & \\
\hline Prkrir & 3.4 & 561755 & $\begin{array}{l}\text { Protein-kinase, interferon-inducible double stranded RNA dependent inhibitor, } \\
\text { repressor of (P58 repressor) }\end{array}$ & 72981 & \\
\hline Ptger2 & 3.0 & 912597 & Prostaglandin E receptor 2 (subtype EP2) & 19217 & \\
\hline
\end{tabular}


Table 2: Select Gene Expression Changes Mediated by I5-HETEa (Continued)

\begin{tabular}{|c|c|c|c|c|c|}
\hline Rin I & -1.9 & 478326 & Ras and Rab interactor I & \multicolumn{2}{|l|}{225870} \\
\hline Ywhag & 4.1 & 606287 & $\begin{array}{l}\text { 3-monooxygenase/tryptophan 5-monooxygenase activation protein, gamma } \\
\text { polypeptide }\end{array}$ & \multicolumn{2}{|l|}{22628} \\
\hline \multicolumn{6}{|c|}{ G-Protein Coupled Receptor Protein Signaling Pathway [2I] } \\
\hline Olfr I 303 & -2.0 & 366625 & Olfactory receptor 1303 & 258397 & \\
\hline Olfr316 & -1.9 & 903210 & Olfactory receptor 316 & 258064 & \\
\hline Olfr435 & -3.2 & 810459 & Olfactory receptor 435 & 258647 & \\
\hline Slc19a2 & 1.9 & 763767 & Solute carrier family 19 (thiamine transporter), member 2 & 116914 & \\
\hline \multicolumn{6}{|c|}{ Cell-Cell Signaling [2I] } \\
\hline Wnt6 & 2.0 & 590115 & Wingless-related MMTV integration site 6 & 22420 & \\
\hline \multicolumn{6}{|c|}{ Development [2I] } \\
\hline Egfl4 & -2.2 & 914308 & EGF-like-domain, multiple 4 & 269878 & \\
\hline Lrp6 & -2.3 & 691244 & Low density lipoprotein receptor-related protein 6 & 16974 & \\
\hline Pgf & 2.9 & 932795 & Placental growth factor & 18654 & \\
\hline \multicolumn{6}{|c|}{ Metabolism [20] } \\
\hline Atpla2 & 2.1 & 684165 & ATPase, $\mathrm{Na}+/ \mathrm{K}+$ transporting, $\alpha 2$ polypeptide & 98660 & \\
\hline Atp2cl & 2.0 & 388850 & ATPase, $\mathrm{Ca}^{2+}$ sequestering & 235574 & \\
\hline Echdc3 & 2.2 & 331450 & Enoyl Coenzyme A hydratase domain containing 3 & 67856 & \\
\hline HsdI7b4 & 2.2 & 303973 & Hydroxysteroid (17-beta) dehydrogenase 4 & 15488 & \\
\hline Mmp9 & -12.3 & 710293 & Matrix metalloproteinase 9 & 17395 & \\
\hline Oas3 & -3.0 & 487213 & 2'-5' oligoadenylate synthetase 3 & 246727 & [16] \\
\hline \multicolumn{6}{|c|}{ Carbohydrate Transport [2I] } \\
\hline Slc35a4 & 2.5 & 318829 & Solute carrier family 35 , member A4 & 67843 & \\
\hline \multicolumn{6}{|c|}{ Protein Transport [2I] } \\
\hline Exoc2 & 3.0 & 498825 & Exocyst complex component 2 & 66482 & \\
\hline Nupl2 & 2.1 & 868036 & Nucleoporin like 2 & 231042 & \\
\hline Rab20 & 2.0 & 410549 & RAB20, member RAS oncogene family & 19332 & \\
\hline Rap2b & 2.2 & 471908 & RAP2B, member of RAS oncogene family & 74012 & \\
\hline Rheb & 1.9 & 653270 & RAS-homologue enriched in brain & 19744 & \\
\hline Zfyve20 & 2.9 & 669220 & Zinc finger, FYVE domain containing 20 & 78287 & \\
\hline \multicolumn{6}{|c|}{ Protein Ubiquitination [2I] } \\
\hline Trim 12 & 2.7 & 454451 & Tripartite motif protein 12 & 76681 & \\
\hline Trim34 & 2.9 & 600486 & Tripartite motif protein 34 & 94094 & \\
\hline \multicolumn{6}{|c|}{ Differentiation [2I] } \\
\hline Ndrg2 & 2.1 & 468211 & $\mathrm{~N}$-myc downstream regulated gene 2 & 29811 & \\
\hline \multicolumn{6}{|c|}{ Other } \\
\hline Pik3apl & 2.0 & 646764 & Phosphoinositide-3-kinase adaptor protein I & 83490 & [16] \\
\hline
\end{tabular}

a Transcripts altered $\geq 1.8$-fold $(p \leq 0.025)$ in I5(S)-HETE-treated RAW 264.7 cells that are associated with specific genes or gene products correlated to malaria (referenced in column 6 ) or genes that are classified with specific over-expressed GO biological processes in malaria models (referenced with biological process heading), are shown in the table. Fold changes (FC) represent the average of three independent biological experiments. Bold FC indicate that multiple probes gave analogous results (average FC is shown). 


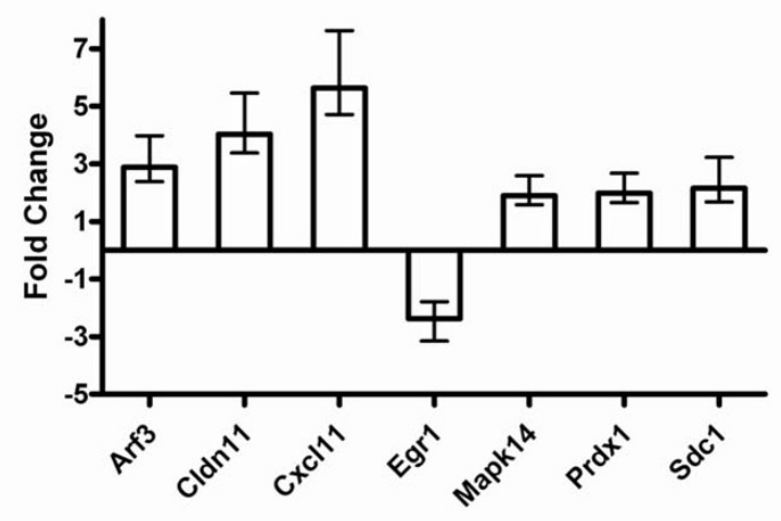

Figure 4

Quantitative real-time RT-PCR validation of microarray results. RAW 264.7 cells were stimulated with 0.1 $\mu \mathrm{g} / \mathrm{mL}$ LPS and treated with $40 \mu \mathrm{M}$ I5-HETE for $24 \mathrm{~h}$ prior to RNA extraction. Fold-changes (treated stimulated cells relative to stimulated cells) are shown ( $\bar{X} \pm 99 \%$ confidence interval for quadruplicate measurements of $n=3$ biological replicates). Abbreviations: Arf3 (ADP-ribosylation factor 3), Cldn I I (claudin I I), Cxcl I (chemokine (C-X-C motif) ligand II), Egrl (early growth response I), Mapk 4 (mitogen-activated protein kinase I4), $\operatorname{Prdx} I$ (peroxiredoxin I), and SdcI (syndecan I).

Ptpn14, which has alleged involvement in cell adhesion, were also induced by 15-HETE.

\section{Leukocyte extravasation and chemotaxis}

The inflammatory response to malaria, both acute and chronic, follows a predictable sequence of events. Initial vascular changes precede increases in permeability, which ultimately causes oedema. Enhanced cytoadherence results in the accumulation, adherence, and migration of leukocytes through vascular endothelium. Molecular mediators are subsequently released and contribute to both the immune response and recruitment/activation of effector cells. Overwhelming evidence demonstrates that the pathophysiology of malaria involves both systemic and local cytokine release. The recruitment of phagocytes around cerebral capillaries has been observed in CM and likely explains increased chemotaxis and chemokinesis [31]. CM is a severe complication of P. falciparum infection that is characterized by cytoadherence in cerebral microvasculature. Accumulation of Hz-loaded monocytes has been observed in brains of CM victims [32] and may contribute to the disruption of endothelial basement membrane and subsequent extravasation of blood cells [26]. Importantly, blood brain barrier (BBB) destruction and enhanced vascular permeability/oedema are major factors associated with CM $[33,34]$.

A potential contribution of 15-HETE toward increased vascular permeability has been examined in the lung. Administration of this hydroxylated fatty acid was shown to increase respiratory oedema fluid production [35], suggesting a role as an inflammatory mediator. The current analysis identified the "Leukocyte Extravasation Signaling" pathway as being significantly $(p=0.015)$ affected by 15-HETE. Specifically, the steady-state expression of Arhgap12, Cldn11, Crkl, Mapk14, and Ptk2b was up-regulated. Although 15-HETE is generally considered to have anti-inflammatory properties, activation of a large group of genes encoding inflammatory response molecules was observed (Table 2).

\section{I5-HETE and MMP9 Regulation}

15-HETE was recently shown to enhance IL1 $\beta$ expression and MMP9 activity in human monocytes [26]. The current study identified a different response to 15-HETE. While $I l 1 b$ mRNA was elevated in 15-HETE treated LPS-stimulated RAW 264.7 cells, Mmp9 mRNA was down-regulated (-4.8-fold by qRT-PCR). Mmp9 expression can be regulated through a variety of signaling cascades including NF$\kappa \mathrm{B}, \mathrm{p} 38 \mathrm{MAPK}$, and ERK1/2 pathways [36]. It was proposed that enhanced regulation of IL1B and MMP9 by 15HETE in human monocytes may be associated with NF- $\kappa$ B signaling [26] based on reports demonstrating NF- $\mathrm{B}$ mediated MMP9 expression in LPS-stimulated RAW 264.7 cells [36]. This mechanism seems unlikely given that 15HETE has been shown to impair NF-кB-mediated expression of $i$ NOS in LPS-stimulated RAW 264.7 cells [13]. Furthermore, PPAR $\gamma$ ligands have been shown to repress NF$\kappa \mathrm{B}$ signal transduction $[37,38]$ and inhibit $M M P 9$ expression, secretion, and activity in macrophages and vascular smooth muscle cells [39-41], in accord with the results of this study.

\section{Conclusion}

The complex innate and adaptive host immune responses to malaria are triggered by the presence of $P$. falciparum parasites, composite native $\mathrm{Hz}, \mathrm{Hz}$-derived lipid peroxidation products, and other cellular debris. A reductionist examination of the cellular response to two individual constituents of native $\mathrm{Hz}, \mathrm{BH}$ and $\mathrm{HNE}$ [12], implicated a significant role for lipid peroxidation products in macrophage immuno-modulation. Consequently, the global response of macrophage-like cells to 15-HETE was explored. 15-HETE has previously been implicated as having a functional role in a variety of cellular processes such as inflammation, asthma, carcinogenesis, and atherosclerosis.15-HETE can be incorporated into membrane lipids and alter both vascular tone and EC permeability [14], 
supporting a potential role in malaria pathogenesis as well. In the current study, the response to 15-HETE was significantly associated with altered expression of "lipid metabolism" and "small molecule biochemistry" genes. Several genes related to "cytoadherence", "leukocyte extravasation", and "inflammatory response" were also differentially regulated by 15 -HETE treatment. While these change uphold a potential role for 15-HETE in malaria pathogenesis, the small number of expression changes indicates that 15-HETE does not elicit a major response from macrophage-like cells in this model. These results add insight and detail to 15-HETE's effect on gene expression in macrophage-like cells, but there are limitations to any model system. For example, 15-HETE represents but one structural HETE isomer that is associated with $\mathrm{Hz}$; 5-, 8-, 9-, 11-, and 12-HETE have also been identified $[13,42] .5$ - and 15-HETE are reported to be the predominant isomers formed during iron catalyzed or $\mathrm{Hz}$ mediated oxidation of AA [42,43], yet 12-HETE may exert greater biological activity [13]. Current findings suggest that upon phagocytosis, the sum of all species adsorbed to the surface of $\mathrm{Hz}$ likely mediate a synergistic immunomodulatory response. Future studies will address expression changes in primary human monocytes and macrophages in response to native $\mathrm{Hz}$ and $\mathrm{Hz}$-associated lipid peroxidation products.

\section{Authors' contributions}

ACS performed all analyses. ACS and DWW designed the study, wrote and approved the final manuscript.

\section{Acknowledgements}

The Vanderbilt Microarray Shared Resource is supported by the Vanderbilt Ingram Cancer Center (P30 CA68485), the Vanderbilt Digestive Disease Center (P30 DK58404), and the Vanderbilt Vision Center (P30 EY08I26). The VMC Flow Cytometry Shared Resource is supported by the Vanderbilt Ingram Cancer Center (P30 CA68485) and the Vanderbilt Digestive Disease Research Center (DK058404). We thank M. F. Richards for editorial assistance.

\section{References}

I. Schmitt TH, Wilson A, Frezzatti J, Schreier S: Hemin-induced lipid membrane disorder and increased permeability: a molecular model for the mechanism of cell lysis. Arch Biochem Biophys 1993, 307:96-103.

2. Gluzman IY, Francis SE, Oksman A, Smith CE, Duffin KL, Goldberg $\mathrm{DE}$ : Order and specificity of the Plasmodium falciparum hemoglobin degradation pathway. I Clin Invest 1994, 93:1602-1608.

3. Pagola S, Stephens PW, Bohle DS, Kosar AD, Madsen SK: The Structure of malaria pigment $\beta$-haematin. Nature 2000, 404:307-310.

4. Goldie P, Roth EF Jr, Oppenheim J, Vanderberg JP: Biochemical characterization of Plasmodium falciparum hemozoin. Am J Trop Med Hyg 1990, 43:584-596.

5. Schwarzer E, Kuhn H, Valente E, Arese P: Malaria-parasitized erythrocytes and hemozoin nonenzymatically generate large amounts of hydroxy fatty acids that inhibit monocyte functions. Blood 2003, 101:722-728.

6. Schwarzer E, Muller O, Arese P, Siems WG, Grune T: Increased levels of 4-hydroxynonenal in human monocytes fed with malarial pigment hemozoin. FEBS Lett 1996, 338:1 19-122.
7. Poli G, Schaur RJ, Siems WG, Leonarduzzi G: 4-Hydroxynonenal: a membrane lipid oxidation product of medicinal interest. Med Res Rev 2008, 28:569-631.

8. Schwarzer E, Turrini F, Ulliers D, Giribaldi G, Ginsburg H, Arese P: Impairment of Macrophage Functions after Ingestion of Plasmodium falciparum-infected Erythrocytes or Isolated Malarial Pigment. J Exp Med 1992, I76: 1033-104I.

9. Schwarzer E, Arese P: Phagocytosis of malarial pigment hemozoin inhibits NADPH-oxidase activity in human monocytederived macrophages. Biochim Biophys Acta 1996, I3 16:169-175.

10. Fiori PL, Rappelli P, Mirkarimi SN, Ginsburg H, Cappuccinelli P, Turrini $F$ : Reduced microbicidal and anti-tumour activities of human monocytes after ingestion of Plasmodium falciparuminfected red blood cells. Parasite Immunol 1993, I 5:647-655.

II. Nguyen PH, Day N, Pram TD, Ferguson DJ, White NJ: Intraleucocytic malaria pigment and prognosis in severe malaria. Trans $R$ Soc Trop Med Hyg 1995, 89:200-204.

12. Schrimpe AC, Wright DW: Comparative analysis of gene expression changes mediated by individual constituents of hemozoin. Chem Res Toxicol 2009, 22:433-445.

13. Carney CK, Schrimpe AC, Halfpenny K, Harry RS, Miller CM, Broncel M, Sewell SL, Schaff JE, Deol R, Carter MD, Wright DW: The basis of the immunomodulatory activity of malaria pigment (hemozoin). The Journal of Biological Inorganic Chemistry 2006, I I:917-929.

14. Spector AA, Gordon JA, Moore SA: Hydroxyeicosatetraenoic acids (HETEs). Prog Lipid Res 1988, 27:27I-323.

15. Setty BNY, Dampier CD, Stuart MJ: Arachidonic acid metabolites are involved in mediating red blood cell adherence to endothelium. J Lab Clin Med 1995, I 25:608-6I7.

16. Griffiths MJ, Mohammed JS, Popper SJ, Hemingway CA, Kortok MM, Wathen A, Rockett KA, Mott R, Levin M, Newton CR, Marsh K, Relman DA, Kwiatkowski DP: Genomewide Analysis of the Host Response to Malaria in Kenyan Children. The Journal of Infectious Diseases 2005, 19 I:1599-16II.

17. Sexton AC, Good RT, Hansen DS, D'Ombrain MC, Buckingham L, Simpson K, Schofield L: Transcriptional Profiling Reveals Suppressed Erythropoiesis, Up-Regulated Glycolysis, and Interferon-Associated Responses in Murine Malaria. The Journal of Infectious Diseases 2004, 189: 1245-1256.

18. Lovegrove FE, Pena-Castillo L, Mohammad N, Liles C, Hughes TR, Kain KC: Simultaneous host and parasite expression profiling identifies tissue-specific transcriptional programs associated with susceptibility or resistance to experimental cerebral malaria. BMC Genomics 2006, 7:295-3II.

19. Sherry BA, Alava G, Tracey KJ, Martiney J, Cerami A, Slater AFG: Malaria-specific metabolite hemozoin mediates the release of several potent endogenous pyrogens (TNF, MIP-I $\alpha$, and MIP-I $\beta$ ) in vitro, and altered thermoregulation in vivo. Journal of Inflammation 1995, 45:85-96.

20. Schaecher K, Kumar S, Yadava A, Vahey M, Ockenhouse CF: Genome-Wide Expression Profiling in Malaria Infection Revelas Transcriptional Changes Associated with Lethal and Nonlethal Outcomes. Infection and Immunity 2005, 73:609I-6I 00.

21. Ockenhouse CF, Hu W-c, Kester KE, Cummings JF, Stewart A, Heppner DG, Jedlicka AE, Scott AL, Wolfe ND, Vahey M, Burke DS: Common and Divergent Immune Response Signaling Pathways Discovered in Peripheral Blood Mononuclear Cell Gene Expression Patterns in Presymptomatic and Clinically Apparent Malaria. Infection and Immunity 2006, 74:556I-5573.

22. Muehlenbachs A, Fried M, Lachowitzer J, Mutabingwa TK, Duffy PE: Genome-Wide Expression Analysis of Placental Malaria Reveals Features of Lymphoid Neogenesis during Chronic Infection. The Journal of Immunology 2007, 179:557-565.

23. Ylostalo J, Randall AC, Myers TA, Metzger M, Krogstad DJ, Cogswell FB: Transcriptome Profiles of Host Gene Expression in a Monkey Model of Human Malaria. The Journal of Infectious Diseases 2005, 191:400-409.

24. Boutlis CS, Yeo TW, Anstey NM: Malaria tolerance - For whom the cell tolls? Trends Parasitol 2006, 22:37I-377.

25. Schwarzer E, Skorokhod OA, Barrera V, Arese P: Hemozoin and the human monocyte - a brief review of their interactions. Parassitologia 2008, 50: I43-145.

26. Prato M, Giribaldi G, Polimeni M, Gallo V, Arese P: Phagocytosis of hemozoin enhances matrix metalloproteinase- 9 activity and TNF- $\alpha$ production in human monocytes: role of matrix met- 
alloproteinases in the pathogenesis of Falciparum malaria. The Journal of Immunology 2005, 175:6436-6442.

27. Skorokhod OA, Alessio M, Mordmuller B, Arese P, Schwarzer E: Hemozoin (malarial pigment) inhibits differentiation and maturation of human monocyte-derived dendritic cells: a peroxisome proliferator-activated receptor- $\gamma$-mediated effect. The Journal of Immunology 2004, 173:4066-4074.

28. Hage T, Sebald W, Reinemer P: Crystal structure of the interleukin-4/receptor $\alpha$ chain complex revelas a mosaic binding interface. Cell 1999, 97:27I-28I.

29. Bolick DT, Orr AW, Whetzel A, Srinivasan S, Hatley ME, Schwartz MA, Hedrick CC: 12/I5-Lipoxygenase regulates intercellular adhesion molecule-I expression and monocyte adhesion to endothelium through activation of RhoA and Nuclear Factor-kappaB. Arterioscler Thromb Vasc Biol 2005, 25:230I-2307.

30. Patricia MK, Kim JA, Harper CM, Shih PT, Berliner JA, Natarajan R, Nadler JL, Hedrick CC: Lipoxygenase products increase monocyte adhesion to human aortic endothelial cells. Arterioscler Thromb Vasc Biol 1999, 19:2615-2622.

31. Howard RJ, Gilladoga AD: Molecular studies related to the pathogenesis of cerebral malaria. Blood 1989, 74:2603-26I8.

32. Silamut K, Phu NH, Whitty C, Turner GDH, Louwrier K, Mai NTH, Simpson JA, Hien TT, White NJ: A quantitative analysis of the microvascular sequestration of malaria parasites in the human brain. Am J Pathol 1999, I 55:395-4I0.

33. Patnaik JK, Das BS, Mishra SK, Mohanty S, Satpathy SK, Mohanty D: Vascular clogging, mononuclear cell margination, and enhanced vascular permeability in the pathogenesis of human cerebral malaria. Am J Trop Med Hyg 1994, 5 I:642-647.

34. Adams S, Brown H, Turner G: Breaking down the blood-brain barrier: Signaling a path to cerebral malaria? Trends Parasitol 2002, 18:360-366.

35. Johnson H, McNee M, Sun F: I5-Hydroxyeicosatetraenoic acid is a potent inflammatory mediator and agonist of canine tracheal mucus secretion. Am Rev Respir Dis 1985, I3 I:917-922.

36. Rhee JW, Lee KW, Kim D, Lee Y, Jeon OH, Kwon HJ, Kim DS: NFkappaB-dependent regulation of matrix metalloproteinase-9 gene expression by lipopolysaccharide in a macrophage cell line RAW 264.7. J Biochem Mol Biol 2007, 40:88-94.

37. Zambon A, Gervois P, Pauletto P, Fruchart J-C, Staels B: Modulation of hepatic inflammatory risk markers of cardiovascular diseases by PPAR-alpha activators: clinical and experimental evidence. Arterioscler Thromb Vasc Biol 2006, 26:977-986.

38. Jiang C, Ting AT, Seed B: PPAR- $\gamma$ agonists inhibit production of monocyte inflammatory cytokines. Nature 1998, 391:82-86.

39. Ricote M, Li AC, Willson TM, Kelly CJ, Glass CK: The peroxisome proliferator-activated receptor- $\gamma$ is a negative regulator of macrophage activation. Nature 1998, 391:79-82.

40. Marx N, Schonbeck U, Lazar MA, Libby P, Plutzky J: Peroxisome proliferator-activated receptor gamma activators inhibit gene expression and migration in human vascular smooth muscle cells. Circ Res 1998, 83:1097-I 103.

4I. Marx N, Sukhova G, Murphy C, Libby P, Plutzky J: Macrophages in human atheroma contain PPARgamma: differentiationdependent peroxisomal proliferator-activated receptor gamma (PPARgamma) expression and reduction of MMP-9 activity through PPARgamma activation in mononuclear phagocytes in vitro. Am J Pathol 1998, 153:17-23.

42. Green MD, Xiao L, Lal AA: Formation of hydroxyeicosatetraenoic acids from hemozoin-catalyzed oxidation of arachidonic acid. Mol Biochem Parasitol 1996, 83:183-188.

43. Fridovich SE, Porter NA: Oxidation of arachidonic acid in micelles by superoxide and hydrogen peroxide. I Biol Chem 198I, 256:260-265.

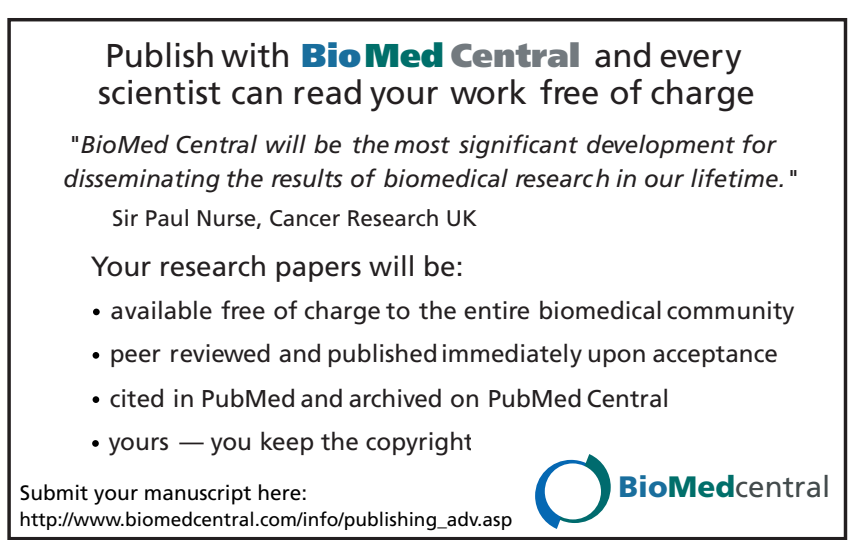

